\title{
Transitivity Analysis of Mariam's Character in A Thousand Splendid Suns
}

\author{
Farah Rauf \\ Government Girls High School Jamrud, KPK \\ Amjad Saleem \\ Assistant Professor, Department of English and Applied Linguistics \\ University of Peshawar
}

\begin{abstract}
This study investigates the portrayal of the central character, Mariam, in A Thousand Splendid Suns through the framework of Transitivity based on Halliday's Systemic Functional Linguistics (SFL). The study has analyzed some important events in Mariam's life such as her childhood, her marital life, and the act of murdering her husband towards the end of the novel. A clause-by-clause analysis reveals that Mariam is assigned mental processes more than material, verbal, and relational processes in the beginning of the novel. Within mental processes, a majority of the processes are cognitive which illustrate that Mariam is a rational person. In contrast, a large number of verbal processes assigned to the Mullah, a religious figure, especially on the eve of Mariam's wedding, suggest the influential and controlling role played by the religious/orthodox segments in the Afghan society as depicted in the novel. Towards the end of the novel, there is a shift in the use of material processes from Rasheed to Mariam which suggests the transfer of 'power' from one to the other, culminating in the murder of Rasheed at Mariam's hand. The study shows the transformation of Mariam's character from an 'innocent' and docile person into a powerful and empowered woman who takes her fate in her own hands.
\end{abstract}

Keywords: Transitivity, Systemic Functional Linguistics, Systemic Functional Grammar, process types, participant types, circumstances

\section{Introduction}

Systemic Functional Linguistics (SFL) is an approach to the study of language which argues that language is a system of lexical and grammatical choices influenced by the context of use. It is a descriptive and interpretive approach that views language as a 'strategic, meaning making resource' (Eggins 1994:1) beyond its formal structure (Halliday 1985, 1994; Matthiessen, 1995; Martin \& Rose, 2003). Systemic Functional Linguistics views language as a 'social semiotic system', where the connection between the form and its meaning is socially and culturally determined. According to Martin (2016), the descriptive and explanatory quality of grammar as meaning making resource distinguishes SFL theory from other linguistic theories (p.35). In other words, Systemic Functional Linguistics provides researchers with a grammar called Systemic Functional Grammar (SFG) which explains systematically how linguistic features used in a text make meanings in context. Systemic Functional Grammar 
(SFG) offers a variety of tools such as Mood, Modality and Transitivity for linguistic analysis. These tools and resources are employed to describe, analyze and interpret language beyond its formal/abstract structure and focus on the functions of language in social and cultural contexts.

The present study uses transitivity as a theoretical framework to investigate the portrayal of Mariam in Khalid Hosseinni's novel A Thousand Splendid Suns by analyzing the thought processes, feelings, and experiences of the main female character in how she evolves as a person in the course of the novel. This research provides a functional explanation by exploring the transitivity patterns in the description of Mariam and offers insights into her character.

\section{Literature Review}

Transitivity has been extensively applied to many literary and non-literary texts. Halliday in his seminal work on William Goldings' novel The Inheritors (1981) employed transitivity as a framework and opened up a whole new way of linguistic analysis of literary texts. He argues that the transitivity system used in the portrayal of Lok shows his limited cognition, and Lok comes out a powerless and weak character. Burton (1982) used transitivity in her study of Sylvia Plath's autobiographical novel The Bell Jar. She analyzed only one short passage from the feminist point of view by focusing on the character's experience and her perceptions of electric shocks as form of medical treatment. Burton concluded that the transitivity patterns used in the text show unequal power relation between the central character and the other two persons-doctor and nurse.

Similarly, Rashid (2017) analyzed the central character in the novel Burnt Shadows by Kamila Shamsie. The novel is about the life of a Japanese woman Hiroko Tanaka, who is a school teacher by profession and survives the Nagasaki bombing of 1945. Rashid analyses roles played by different participants and their effectuality and non-effectuality in the text from 'subtexts' from four different sections of the novel with each section dealing with different context. In other words, the selection of the 'subtexts' is based on different contexts found in these four sections of the novel. According to the study, Hiroko has been assigned with $65 \%$ roles, Konrad 4\%, Sajjad 13\%, James 4\%, llse 3\%, Raza 6\% and Kim has 3\% of the roles given. While percentages of transitivity concordances roles remain the same for all the four sections of the novel, the dynamism roles score keep on changing. Initially, she comes across a helpless and ineffective being, more of a thinker not a doer; in the last part of analysis, however, she 
emerges as an effective and powerful character who can control the world around her. Using the systemic functional grammar, Gallardo (2006) investigated the gender related features in Bernard Shaw' Pygmalion. Analyzing the dialogues between Eliza and Higgins, Gallardo discovers that Higgins uses material processes very often, where he is the actor and Eliza is the goal of his actions. Gallardo argues that male characters are more concerned with achieving their aims and promoting their professional life whereas female characters are emotional in their relationships. She concludes that men exercise power in accomplishing routine tasks over women.

Illustrating the effectiveness of transitivity analysis in teaching English as a Second Language (ESL), Cunanan (2011) adapts Burton's approach (1982) and investigates the world view of Old Mrs. Grey in Virginia Woolf's essay Old Mrs. Grey. The analysis includes the investigation of different process types and their percentage distribution among the major and minor participants. He found that the essay uses existential processes such as is folded, is lit up, and was gone etc. (35.49\%); material processes such as crawl, twisted, and jerked etc., (19.36\%); mental processes such as wonders, was looking, and saw etc. (15.08\%); and verbal processes (such as says, mumble and pray etc.(15.05\%). Using Halliday's theory of transitivity, Nguyen (2012) studied the main character in a short story 'Heroic Mother' by Hoa Pham, an Australian Vietnamese writer. Nguyen believes that the heroic mother is a lonely and sad person who has no strong ties with her family members. While she is considered lunatic by other, she professes that she is not crazy but posed insanity during war time.

The above review is representative of the application of transitivity to some literary texts. Taking findings from published literature into account, the present research focuses on investigating the transformation of the central female character in the novel A Thousand Splendid Suns and offers an explanation by exploring the transitivity patterns in the description of the character of Mariam.

\section{Methodology and Framework}

The analysis is carried out by using a three-step procedure of Transitivity framed by Burton (1982) in her study of The Bell Jar. The procedure is as follows:

a) Isolating the processes from their participants.

b) Sorting out the different types of processes and finding the participants involved in each type of process. 
c) Setting apart who or what is affected by each process type.

Following Burton, the present study identifies and sorts out all the processes used in the description of Mariam, explains their functions at length, and shows 'who affects whom or what' in the clause system used in the text. In other words, the study of the roles of participants in how they affect the environment or other participants involved, is central to the present analysis. Unlike Burton's model, however, which deals with the main process types only, such as material, mental and relational, this study uses all six types of processes categorized by Halliday (1994): they are: material, mental, relational, verbal, existential, and behavioral. This research thus adopts an eclectic approach i.e. the combination of different approaches by using Halliday's six processes along with Burton's additional classification of processes in her threestep model of transitivity for achieving the objectives of the present study.

A clause is the point of departure in the transitivity analysis of a text. Halliday (2004) defines clause as the central processing unit in the lexicogrammar - in the sense that it in the clause that meanings of different kinds are mapped into an integrated grammatical structure (p.10). Since the present study analyzes all the clauses used in the portrayal of Mariam for the study of transitivity patterns, the analysis will be limited to the discussion of the roles of participants and processes used.

Selection of the text for the analysis is based on critical and decisive phases in Mariam's life as described in the novel. These phases are divided into sections for better analysis. The first section is labeled as 'Mariam's Childhood' because it deals with Mariam's early life when she was only five years old and had no sense of the word harami-a word often used to refer to her illegitimate birth. An extract of thirteen lines from chapter 1 is selected which sets the stage for plot of the novel and describes the characters of Mariam as a child. The second section is called 'Mariam's Marriage Ceremony' and is concerned with one of the significant events in Mariam's life where she was forced to marry a man whom she meets for the first time. Two extracts of nineteen lines and six lines respectively from chapter 8 of the novel are chosen for the analysis of transitivity structure. The third section entitled 'Mariam's Marital Life' analyses three extracts of fourteen lines from chapter 10, twelve lines from chapter 13 and sixteen lines from chapter 15, respectively. These extracts portray Mariam's life as a married person and her role as a wife. The fourth section labeled 'Mariam's Final Decision' explores the evolution and development of Mariam's personality towards the end of the novel. An extract of thirty-two 
lines, dealing with how Mariam murders Rasheed in defending Laila, from chapter 45 is selected for transitivity analysis.

The traditional notion of transitivity in English syntax is concerned with the verb followed by its object in a sentence. Using the same concept, Halliday (1994) has elaborated and added to the system of transitivity expanding it to a clause and its meaning. In Halliday's system, the subject in a clause performs many roles such as that of an actor, senser, carrier of an attribute, token, sayer, and behaver, etc. A clause thus represents the experiences; doings, happenings, feelings, thoughts and other 'goings-on' in ones 'mind and the outside world.

Transitivity is a very useful and productive tool for researcher that provides them with a means to realize the experiences embedded in the structure of a clause. Halliday (1985) defines Transitivity as follows:

A fundamental property of language is that it enables human beings to build a mental picture of reality, to make sense of their experience of what goes on around them and inside them. ...Our most powerful conception of reality is that it consists of "goingson": of doing, happening, feeling, and being. These goings-on are sorted out in the semantic system of language and expressed through the grammar of the clause... This... is the system of TRANSITIVITY. Transitivity specifies the different types of processes that are recognized in the language and the structures by which they are expressed. (p.101)

Elaborating on the same concept, Hassan (1988) reasons that transivity is concerned with the coding of the goings on: who does what in relation to whom/what, where, when how and why (p.63). Transitivity uncovers certain mind-sets or ideologies invested in a text. Likewise, Simpson (1993) asserts that transitivity generally refers to how meanings are represented in the clause (p.88). Berry (1975) describes the transitivity choices in the following words:

In English grammar, we make choices between different types of process, between different types of participants, between different types of circumstances, between different roles of participants and circumstances, between different ways of combining processes, participants and circumstances. These choices are known collectively as the transitivity choices. (p.150) 
A clause, according to transitivity theory, has three parts: participants, processes and circumstances. Participants are usually realized by nominal groups, processes by verbal groups and circumstance by prepositional or adverbial groups. The role of participants in a clause is determined by the choice of processes in it, making a process type as an integral part of the analysis (see the table below). Halliday (1976) describes processes as "anything that can be expressed by a verb: event, whether physical or not, state, or relation" (p.159).

\begin{tabular}{|c|c|c|}
\hline Process & Participants & Examples \\
\hline Material & Actor, Goal & She (actor) kicks (material process) the ball (goal). \\
\hline Mental & Senser, Phenomenon & $\begin{array}{l}\text { She (senser) thought (mental process) of her baby } \\
\text { (phenomenon). }\end{array}$ \\
\hline Relational & Carrier and Attribute, Token and Value & $\begin{array}{l}\text { a. She (carrier) is (relational process) good (attribute). } \\
\text { b. He (token) is (relational process) a doctor (value). }\end{array}$ \\
\hline Behavioral & Behaver & He (behaver) coughed (behavioral process). \\
\hline Verbal & Sayer, Receiver, Verbiage & $\begin{array}{l}\text { She (sayer) asked (verbal process) me (receiver) } \\
\text { some questions (verbiage). }\end{array}$ \\
\hline Existential & Existent & $\begin{array}{l}\text { There are (existential process) flowers (existent) in } \\
\text { the garden. }\end{array}$ \\
\hline
\end{tabular}

Table 1: Process type and the accompanying participants

The main purpose of the present study is to decipher the experiential meanings and authorial ideology that underpins the description of Mariam, using transitivity as a tool of analysis.

\section{Mariam's Childhood}

\section{Analysis}

There is a total of 21 clauses in the text about Mariam's childhood, out of which 13 use mental processes, 3 make use of relational processes, 4 have employed verbal processes and only one clause has used a material process.

Out of 13 clauses of mental processes, eight are cognitive processes such as understand, know, surmise, three are processes of perception e.g., see and two clauses have used the processes of affection i.e. appreciate and feel. A large of number of mental processes suggests that Mariam's faculty of cognition is well developed as compared to her other mental faculties such as perception and affection. Mariam is assigned no verbal processed and she is portrayed as a quiet and introvert person who does not give expression to her thoughts. The three relational processes used in the portrayal of Mariam represent the qualities and attributes of the character: old and older, for example, are used for Mariam and describes Mariam's age and her identity with respect to her society. Since Mariam has not been given the role of an actor in the text, no significant action is performed by her which shows her as someone physically inactive and not in control of what goes around her. 


\section{Mariam's Wedding Ceremony}

There is a total of 37 clauses, out of which 13 clauses have used verbal processes, 9 are of material processes, 8 are behavioral, 3 mental, 3 relational, and only one clause has employed the existential process. The analysis shows that the number of verbal processes used is large as compared to the rest of the processes. Out of the 13 verbal processes, the role of the Sayer is performed 9 times by the Mullah, whereas Mariam, Rasheed, and Jalil perform the role of the Sayer only once each. Such an extended role for the Mullah as the Sayer indicates the power and clout he carries in the Afghan society as depicted in the novel. The material processes used in 9 clauses are: gave, reached out, flicked, exchanged, fished, tried, help and forcing. All these processes are material intentional processes i.e., the actions are performed with the intention of the Actor. Most of the material intentional processes are given either to Rasheed or to other participants but not to Mariam. The absence of material intentional processes in the case of Mariam shows how she might have been forced into marriage with Rasheed without her consent. As far as relational processes are concerned, there are three Relational processes which are attributive in nature. Rasheed's body parts (nails) are Carriers two times in clauses of the Attributes yellow-brown, curling, lifting respectively. On the other hand, we can see that Mariam's finger band is a Carrier of an Attribute little tight. The negative attributes assigned to Rasheed's nails reveal him as a careless and rough man. Likewise, the negative attribute assigned to Mariam's finger band gifted to her by Rasheed anticipates the hardships Mariam will face at the hands of Rasheed.

The mental processes used in 3 clauses are reminded, feel, and sense and Mariam is the Senser in all them. The Phenomenon of the sound of dry leaves crushed underfoot in clause 7 has an unwelcome connotation which indicates the nature of marriage between Mariam and Rasheed.

Given very few material processes are used for Mariam, her role as an Actor in the text is limited. In one of the clauses, the Goal of her action is band which is an inanimate thing, suggesting that Mariam is incapable of influencing her environment except insignificant things such as a band. In the same clause, Rasheed is an Actor and the Goal is Mariam herself showing how patriarchy works in Afghan society where men think of women as weak and timid creatures who cannot do anything without a man's help.

\section{Mariam's Marital Life}


Out of the 71 clauses in the text selected for the analysis, 47 are clauses of material processes, 13 are mental, and 9 are relational. Behavioral and existential processes have appeared once each. The material processes used in clauses are unpacked, drew, washed, kneading, folding, swept, cut, wrapped etc. The actions washed, swept and set in these clauses are used in relation to home chores. Some material processes used in clauses such as left, shed, dragged, sat, flipped, slurping are used to refer to activities either outside home or work at home. Mariam is given the principal role of an Actor in these actions. She is the initiator of all the actions done by her where the Goals are her clothes, a pail of water, the cobwebs, a knife, some carrots, fresh dough etc. These Goals are related to the household chores and shows how Mariam's world is confined to domestic activities highlighting the process of her domestication. Among the mental processes, 6 are perceptive such as shown, listened, see etc., five are cognitive i.e. thought, think, know, and wondered and only two are affective processes e.g., dreaded and infuriate. The role of Senser is assigned to Mariam in 9 clauses with the baby and Rasheed's bad behavior as Phenomena. This indicates how Mariam is subjected to domestic and emotional violence by her husband.

As for as the relational processes, six are attributive relational processes whereas three are relational identifying processes. The words nothing and burden are Attributes and are used for the Carrier she i.e., Mariam. The negative attribute burden appears two times for Mariam which indicates the intensity of the toxic relationship between Mariam and Rasheed, and how Mariam is looked down upon by her husband.

\section{Mariam's Final Decision}

Towards the end of the novel Mariam takes an extreme step and decides to kill her husband. A total of 44 clauses related to Mariam's decision and act of murdering her husband are selected for analysis. There are 30 material processes, 19 mental, and 2 relational and verbal processes each. Mariam is assigned the role of the Actor in 14 clauses, where she is the initiator of almost all the actions taking place with Rasheed as the goal in several clauses. On other hand, when Rasheed is the actor, his own body parts such as head, the keys, his gun and Zalmai are the goals. There is not a single clause where Mariam is the goal of his actions. Rasheed, in this part of the novel, emerges as a passive participant whose role as an actor is very limited and is rather the goal of Mariam's actions in the entire text. The analysis reveals significant 
changes in the character of Mariam: she emerges as a dominant and dynamic character in the text.

Mariam is the main participant of mental processes used. She is given the role of a Senser in 16 clauses, whereas Rasheed performs the role of Senser in 3 clauses. The clauses assigned to Rasheed are all mental perceptive processes the Phenomenon of which is either Mariam, or he himself. He is not assigned cognitive processes which indicate his limited faculty of cognition and understanding as opposed to Mariam who emerges as a person of clear understanding and power of decision making. In the two verbal processes used here, Mariam is the Sayer. Her voice is loud and clear in this text now while Rasheed's voice is absent. This shows the development of Mariam as an expressive person who finds her voice and gives vent to her thoughts towards the end of novel.

\section{Discussion and Conclusion}

This study aimed at investigating transitivity patterns in exploring the character of Mariam as portrayed in A Thousand Splendid Suns. The use of a large number of mental processes in depicting the character of Mariam shows the cognitive ability of Mariam and the rational side of her personality. Her murdering of Rasheed is shown to be the result of her rational thinking: she kills him to free herself from lifelong sufferings inflicted on her by patriarchy as symbolized by Rashid. Mariam is someone who thinks and finally uses her rational faculty and decides to take matters in her own hand. This is in contrast to how Rasheed is portrayed: assigned with only few processes of cognition, Rashid's character is marked by ego and anger which does not allow him to think rationally and he comes out as a lop-sided and imbalanced character.

There is an obvious shift in the use of a greater number of material and verbal processes for Mariam towards the end of the novel: Mariam is finally in possession of her voice which materializes into actions culminating in the death of Rashid. Mariam's stigmatized and marginalized status because of her illegitimate birth and her gender is over and she becomes the symbol of woman empowerment in the novel. She challenges the established norms of her society and carves an individualistic identity for herself. The use of a large number of material processes for Mariam towards the end of novel shows the shift in the power dynamics. In the beginning of the novel, the control and power was in the hands of men, however, it is transferred to women towards the end of novel. 
References
Berry, M. (1975). Introduction to systemic linguistics. London: Batsford.

Burton, D. (1982). Through Dark Glasses through Glass Darkly. In: Carter, R., Ed., Language and Literature. London: Allen and Unwin. 195-214.

Eggins, S. (1994). An Introduction to Systemic Functional Linguistics. London: Pinter.

Cunanan, B.T. (2011). Using Transitivity as Framework in Stylistic Analysis of Virginia Woolf's Old Mrs. Grey. Asian EFL Journal, 54. Retrieved from http://www.asian-efljournal.com/PTA/Volume-54-bc.pdf.

Gallardo, B. C. (2006). Analysis of a Literary Work Using Systemic-Functional Grammar. In 33rd International Systemic Functional Congress, São Paulo. Retrieved from http://www. pucsp. br/isfc/proceedings/Artigos (Vol. 20).

Halliday, M.A. K. (1981). Linguistic Function and Literary Style: An Inquiry into the

Language of William Golding's the inheritors. In Donald C. Freeman (Ed.) Esaay in Modern Stylistics (pp. 325-60). London: Methuen.

Halliday, M.A.K. (1976). System and Function in Language: Oxford University Press

Halliday, M.A.K. (1985). An Introduction to Functional Grammar. London: Edward Arnold.

Halliday, M.A.K. (1994). An Introduction to Functional Grammar. (2 ${ }^{\text {nd }}$ Ed.). London: Edward Arnold.

Halliday, M.A.K., \&Matthiessen, C. (2004). An Introduction to Functional Grammar.( ${ }^{\text {rd }}{ }^{2}$ d. $)$ London: Hodder Arnold.

Hasan, R. (1988). The Analysis of One Poem: Theoretical Issues in Practice. In Birch, D., \&O’Tool, M. (Eds.). Functions and Styles. London: Edward Arnold.

Martin, J. R. (2016). Meaning matters: a short history of systemic functional linguistics. Word. 62 (1). (pp. 35-8).

Martin, J., \& Rose, D. (2003). Working with Discourse: Meaning Beyond the Clause,

London: Continuum.

Matthiessen, C. (1995). Lexico-grammatical Cartography: English Systems. Tokyo:

International Language Science Publishers.

Nguyen, T. (2012). Transitivity Analysis of Heroic Mother by Hoa Pham. International Journal of English Linguistics, 2 (4), 85-100. 
UNIVERSITY OF CHITRAL JOURNAL OF LINGUISTICS AND LITERATURE

VOL. 5 | ISSUE II | JULY - DEC | 2021 G= IIF ISSN (E): 2663-1512, ISSN (P): 2617-3611

https://doi.org/10.33195/jll.v5iII.334

Rashid, A. (2017). Transitivity Analysis of Hiroko's Character in Burnt Shadows. Unpublished Thesis: COMSATS Institute of Information Technology. Retrieved from http://www.isfla.org/Systemics/Print/Theses/Rashid-MS-2017.pdf

Simpson, P. (1993). Language, Ideology and Point of View. London: Routledge.

\begin{tabular}{|l|l|}
\hline (C) 12021 by the author. Licensee University of Chitral, Journal of \\
By & $\begin{array}{l}\text { @inguistics \& Literature, Pakistan. This article is an open access article } \\
\text { distributed under the terms and conditions of the Creative Commons } \\
\text { Attribution (CC BY) (http://creativecommons.org/licenses/by/4.0/). }\end{array}$ \\
\hline
\end{tabular}

